\title{
Can the Insider-Outsider Theory Explain Unemployment Hysteresis in OECD Countries?
}

\author{
Dimitrios Bakas ${ }^{a, b \dagger}$ and Yousef Makhlouf $a$

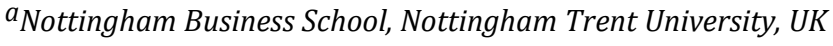 \\ ${ }^{b}$ Rimini Centre for Economic Analysis (RCEA), Canada
}

\begin{abstract}
Insider-outsider theory is often used as a basis for explaining the hysteretic behaviour of unemployment. Despite this, there is no empirical evidence about the validity of this theory on explaining the persistence of unemployment. This paper addresses this gap, using various labour market proxies of insiders' power for the OECD countries over 1960-2013 and employing panel unit root tests that exploit the information contained in these proxies. The results show that although the unemployment rate exhibits a pronounced hysteretic behaviour in OECD countries, this behaviour is reversed once we account for the insider-outsider proxies. Our findings thus validate the role of the insider-outsider theory as a key source of unemployment hysteresis.
\end{abstract}

JEL Classification: C23, E24, J51, J64

Keywords: Insider-outsider theory, Hysteresis, Unemployment, Panel unit root tests

\footnotetext{
${ }^{\dagger}$ Acknowledgments: We would like to thank the Associate Editor, Raoul Minetti and two anonymous referees for their constructive comments and helpful suggestions. In addition, we would like to thank Robert Ackrill, Neil Kellard, Christopher Lalley, Georgios Magkonis and Piers Thompson for their valuable comments and suggestions on earlier versions of this work. Any remaining errors are the responsibility of the authors. The authors declare that they have no conflict of interest.

Dimitrios Bakas: Nottingham Business School, Nottingham Trent University, 50 Shakespeare Street, Nottingham, NG1 4FQ, United Kingdom. E-mail: dimitrios.bakas@ntu.ac.uk, Phone: +44 (0)115 8484191 (Corresponding Author).

Yousef Makhlouf: Nottingham Business School, Nottingham Trent University, 50 Shakespeare Street, Nottingham, NG1 4FQ, United Kingdom. E-mail: yousef.makhlouf@ntu.ac.uk, Phone: +44 (0)115 8484190.
} 


\section{Introduction}

An extensive strand of the literature tests the hysteresis in unemployment, a hypothesis which implies that any deviations of unemployment from its natural rate will be permanent, as suggested by Blanchard and Summers (1986, 1987). The empirical literature, however, provides mixed evidence. Whilst some studies have documented evidence of hysteresis, e.g. Mitchell (1993), Røed (1996) and Bakas and Papapetrou (2014), others, such as Jaeger and Parkinson (1994), Arestis and Mariscal (1999) and Camarero and Tamarit (2004), provide evidence against. Noticeably, these studies examine the hysteresis hypothesis using alternative unit root testing techniques and/or different samples and pay no attention to investigate the sources of this phenomenon, which is important to set policies that address the persistence of unemployment.

The hysteresis hypothesis of unemployment (Blanchard and Summers, 1986; 1987) implies that movements in unemployment are characterized by persistence and, thus, temporary shocks to the economy have permanent effects and move the actual level of unemployment away from its equilibrium level. This hypothesis can be translated as the presence of a unit root in the unemployment rate. The rejection of the hysteresis hypothesis implies that unemployment fluctuates around the natural rate, which in turn means that the unemployment rate follows a meanreverting process, and the shocks to the economy have only temporary effects. In this way, the evidence of level stationarity for the unemployment rate would be in support of the natural rate for unemployment (Friedman, 1968 and Phelps, 1968). ${ }^{1}$

The insider-outsider theory has long been used to explain the hysteresis hypothesis of unemployment (Lindbeck and Snower, 1988). According to this theory, as advocated first by

\footnotetext{
${ }^{1}$ See Cross (1988), Røed (1997) and O'Shaughnessy (2011) for an overview of the theoretical and empirical literature on the hysteresis in unemployment.
} 
Blanchard and Summers (1986), hysteresis in unemployment arises from the power of insiders in the wage determination mechanism. Currently employed workers - the insiders - are able to secure wage increases for themselves - above the level of their reservation wage -, since their position is protected by labour turnover costs (such as the costs of hiring, firing and providing firm-specific training) that firms face and, thereby, prevent the unemployed - the outsiders - from competing wages down and force firms to reduce employment. As a result of this mechanism, Blanchard and Summers (1986) and Gottfries and Horn (1987) show that a negative shock in the economy will lead to layoffs of insiders by firms and, thus, to the subsequent rise of job security for the remaining of insiders. The outcome of higher job security is a rise of the insider wage for those remain in the firms, and thereby, the reduction of total labour demand in the economy, which results to unemployment persistence (Lindbeck and Snower, 2001). Insiders' power, hence, reflects labour market rigidities and turnover costs which may affect the level and presistence of unemployment. ${ }^{2}$

A series of studies have explored the relation between rigidities in labour market institutions and the rate of unemployment and find that institutional rigidities play a vital role on explaining unemployment patterns and persistence (see for example Belot and Van Ours, 2001; 2004 and Nickell, 2003). When labour market institutions turn to be more rigid, wages will start to increase. If this push in wages is not compatible with productivity, employment will tend to fall until the point that the higher unemployment in the economy will lead to a downward pressure on the wages that will offset the initial effect of the higher labour market rigidity. Thus, this mechanism can explain the impact of institutional rigidity on the natural rate of unemployment (Saint-Paul, 2004). However, most OECD countries have experienced changes in labour market rigidities over the last decades. For example, many European countries have faced a sharp increase in unemployment

\footnotetext{
${ }^{2}$ See Lindbeck and Snower $(2001,2002)$ for surveys on the literature of the insider-outsider theory.
} 
benefits after the 1960s, while the employment protection legislation index has increased for most of the countries over this period (Nickell, 2003). Furthermore, there is significant heterogeneity of labour market rigidities across the OECD countries (Saint-Paul, 2004). An important dimension of this environment is the power of the insiders which can determine labour market rigidities in the economy (Lindbeck and Snower, 1988 and Berthold and Fehn, 1996).

Despite the widespread use of the insider-outsider theory as the key source of unemployment hysteresis, little is known about its validity empirically, and this is where our main contribution lies. In this way, this paper analyse the nexus between insiders' power, as a proxy of labour market rigidities, and unemployment persistence. To the best of our knowledge, this is the first study that evaluates whether the insider-outsider theory, proxied by the measures of trade union density, coordination of wage-setting and level of wage-bargaining, can explain the persistence of unemployment rate in a sample of OECD countries over the period 1960-2013. These measures can be considered as prominent proxies for the power of insiders. ${ }^{3}$

We, first, use conventional panel unit root tests to examine the behaviour of unemployment rate. Then, our empirical framework extends the panel unit root tests to allow for the presence of covariates in the testing equation of the hysteresis hypothesis for unemployment, see Pesaran et al. (2013). By doing so, we take into account the information that is contained in our insideroutsider covariates, and thus conduct a direct test for the insider-outsider theory. Our results show, first, that using conventional panel unit root tests we find evidence of hysteresis in unemployment for the OECD countries. However, this result is completely reversed, and the unit root in unemployment rate is strongly rejected, once we employ the panel unit root tests allowing for the

\footnotetext{
${ }^{3}$ See Section 2 for more details on the insider-outsider proxies.
} 
insider-outsider covariates. This supports the insider-outsider theory as a key source of the hysteretic behaviour of unemployment and confirms the theoretical foundations of Blanchard and Summers $(1986,1987)$ and Lindbeck and Snower (1988).

In terms of policy, our findings suggest that labour market policies, which increase the power of insiders, like job security regulations and restrained labour market flexibility, can prevent the ability of a country to revert the effects of temporary shocks on unemployment. Consequently, reforms in the direction of lessening the insiders' power through limiting the role of trade union, reforming job security regulations, and/or reducing the wage-bargaining level, can lead to lower unemployment persistence.

The rest of the paper is organized as follows. Section 2 describes the data. Section 3 provides the empirical methodology. Section 4 presents our empirical results, while Section 5 provides further results and robustness checks. Finally, Section 6 concludes.

\section{Data}

We use an unbalanced annual dataset of 21 OECD countries from 1960 to $2013 .{ }^{4,5}$ This is the longest period for which the data for the labour market measures; trade union density, coordination of wage-setting and the level of wage-bargaining, are available. The source of unemployment rate

\footnotetext{
${ }^{4}$ The 21 OECD countries in our sample are: Australia, Austria, Belgium, Canada, Denmark, Finland, France, Germany, Greece, Ireland, Italy, Japan, Netherlands, New Zealand, Norway, Portugal, Spain, Sweden, Switzerland, United Kingdom, United States.

${ }^{5}$ Our unbalanced panel includes 21 OECD countries for which time series data for the unemployment rate and covariates are available in good quality over the total observation period (1960 to 2013). However, in the robustness section, we complement our empirical analysis using a sample of 17 OECD countries where we drop 4 countries (Greece, New Zealand, Portugal and Spain) as their data for the covariates are available for shorter period. Thus, we have a balanced panel of 17 OECD countries that allows us to apply both the CIPSM and CSBM tests of Pesaran et al. (2013) as the latter requires a balanced panel.
} 
(Un. Rate) and trade union density (Union) is the OECD labour force statistics whilst the source of the coordination of wage-setting (Coord) and the level of wage-bargaining $(\mathrm{Wbl})$ is the ICTWSS Database Version 5.1. In addition, we have created the variable Power that consists the first principal component of the three labour market institution covariates (Union, Coord and Wbl). This aggregate measure encapsulates the insiders' power of the three proxies.

Trade union density is the trade union membership as a percentage of wage and salary earners in employment. Trade union activity, which only represents the insiders' interests, is considered as the most obvious source of insiders' power (Lindbeck and Snower, 1988; Layard and Bean, 1989; Emmenegger, 2009 and Davidsson and Emmenegger, 2013). Moreover, we use two proxies of wage-bargaining level. The coordination of wage-setting is a discrete measure, ranging from 5 to 1, reflecting the degree of coordination from economy-wide bargaining to fragmented bargaining, confined largely to firm-level. Additionally, the level of wage-bargaining is a discrete measure that represents the predominant level at which wage bargaining takes place, ranging from 5 (national or central level) to 1 (local or company bargaining level), see van Ours (2015). The high wage-bargaining power of insiders increases the equilibrium rate of unemployment via boosting labour market rigidities (Berthold and Fehn, 1996; Saint-Paul, 2004 and Heidenreich, 2015). Furthermore, bargaining power is positively associated with turnover costs thereby it strengthens the position of insiders relative to outsiders, which enhances the wage pressure and unemployment rate (Lindbeck and Snower, 1988; Berthold and Fehn, 1996; Emmenegger, 2009 and Holmlund, 2014). There are various other potential measures of labour market frictions, such as minimum wages, unemployment insurance, unemployment benefits, employment protection legislation and severance pay (see Holmlund, 2014), however, data availability for these factors is limited. These 
proxies can also influence unemployment persistence through different mechanisms. ${ }^{6}$ The main objective of this paper is to test the role of the insider-outsider theory as a source of hysteresis, however, we explore also whether alternative measures of labour market frictions can explain unemployment persistence. ${ }^{7}$ Finally, our proxies capture the insiders' power but can also reflect these additional factors, e.g. trade unions minimize labour turnover cost by pushing for more job security regulations (Emmenegger, 2009).

Figure 1 presents the evolution of the unemployment rate for the 21 OECD countries against the OECD average for the period 1960-2013. The figure shows the substantial heterogeneity of OECD labour markets. Saint-Paul (2004) illustrates that the observed divergence in unemployment rates across Europe is a real difference in labour markets rather than a statistical artifact since this divergence cannot be explained by obvious measurement issues such as different definitions of unemployment across countries.

\section{- Figure 1 here -}

Table 1 presents summary statistics for the unemployment rate and the covariates for our panel. A high variation in all variables is evident, for example Union ranges from $7.5 \%$ to $84 \%$. Furthermore, the average of both Coord and $\mathrm{Wbl}$ indicates that the wage-bargaining level, and thus the insiders' power, is relatively high in our sample.

\section{- Table 1 here -}

\footnotetext{
${ }^{6}$ See Section 5 for more details on these additional labour market proxies.

${ }^{7}$ We complement our main empirical analysis using these additional measures in the robustness section of the paper. We would like to thank two anonymous referees for drawing our attention to this point.
} 
Table 2 shows the correlation coefficients between the covariates and the unemployment rate. The high correlation between Coord and $\mathrm{Wbl}$ is anticipated since both covariates reflect the wagebargaining level. The positive correlation between Union and wage-bargaining level proxies (Coord and $\mathrm{Wbl}$ ) indicates that all three covariates operate in an analogous manner, i.e., they reflect the power of insiders relative to outsiders.

\section{- Table 2 here -}

\section{Empirical methodology}

To test for the hysteresis hypothesis (i.e., the null hypothesis of the presence of a unit root) in the dynamics of the unemployment rate in our sample, we rely on panel augmented Dickey-Fuller (ADF) unit root tests. Specifically, we use the $M W$ test of Maddala and Wu (1999), the $C H$ test of Choi (2001), the IPS test of Im et al. (2003) and the CIPS test of Pesaran (2007), which accounts for cross-sectional dependence across the countries.

\subsection{Panel unit root tests with covariates}

In the case where the null hypothesis of hysteresis in unemployment is not rejected using the standard tests (MW, CH, IPS and CIPS), we proceed and explore the insider-outsider theory as source of the hysteretic behaviour of unemployment, by employing panel unit root tests that allow for the presence of various labour market proxies as covariates in the panel regression. To do so, we use the CIPSM panel unit root test proposed by Pesaran et al. (2013), which incorporates additional covariates in the augmented Dickey-Fuller panel regression and accounts for a multifactor error structure. Therefore, this test can exploit the information contained in a number of additional covariates (the insider-outsider proxies in our case) that are assumed to share the common factors with the unemployment rate. Following Pesaran et al. (2013), we augment the 
ADF panel regression with the cross-section averages of the lagged levels and first-differences of the unemployment rate and the additional covariates. In particular, we employ the following ADF panel regression:

$$
\begin{gathered}
\Delta U_{i, t}=\alpha_{i}+\beta_{i} t+\phi_{i} U_{i, t-1}+\sum_{j=1}^{p} \delta_{i j} \Delta U_{i, t-j} \\
+c_{i} \bar{U}_{t-1}+\sum_{j=0}^{p} d_{i j} \Delta \bar{U}_{t-j}+e_{i} \bar{Z}_{t-1}+\sum_{j=0}^{p} f_{i j} \Delta \bar{Z}_{t-j}+\varepsilon_{i, t},
\end{gathered}
$$

where $U_{i, t}$ is the unemployment rate for for country $i$ at time $t, \bar{U}_{t}$ and $\bar{Z}_{t}$ are the cross section averages of the unemployment rate and the measures of insiders' power respectively, with $\bar{U}_{t-1}=$ $N^{-1} \sum_{j=1}^{N} U_{j, t-1}$ and $\bar{Z}_{t-1}=N^{-1} \sum_{j=1}^{N} Z_{j, t-1} \cdot{ }^{8}$ Therefore, as suggested by Pesaran et al. (2013), the CIPSM test is based on the average of the individual cross-sectionally augmented ADF $t$-ratios for $\widehat{\phi}_{l}\left(t_{\phi_{i}}\right)$, given as $\operatorname{CIPSM}=N^{-1} \sum_{i=1}^{N} t_{\phi_{i}}(N, T)$.

Simulated critical values of the test are listed in Pesaran et al. (2013). The test rejects the null hypothesis of hysteresis in unemployment (i.e., the unit root null hypothesis) when the value of the statistic is less than the respective critical value. According to Pesaran et al. (2013), the CIPSM test do not show any size distortions for combinations of $N$ and $T$.

Our testing framework, thus, uses an augmented Dickey-Fuller panel regression with the inclusion of alternative measures of labour market (and possible combinations of them) as additional covariates to testing for unit root in the unemployment rate. ${ }^{9}$ In this way, a rejection of the null

\footnotetext{
${ }^{8}$ By utilising this ADF panel regression specification, where the covariates are included in Equation (1) in the form of lagged levels and first-differences of the cross-section averages $\left(\bar{Z}_{t-1}\right.$ and $\left.\Delta \bar{Z}_{t-j}\right)$, the covariate panel unit root test of Pesaran et al. (2013) is unaffected by any potential endogeneity of the covariates. ${ }_{9}^{9}$ As we have explained previously, this test exploits the information contained in a number of covariates that share the common factors with unemployment. Thus, as each covariate depends on the common factors, the test is robust to the endogeneity of the observable factors toward the common factors that determines the unemployment rate.
} 
hypothesis of the presence of a unit root in unemployment rate will lead to the conclusion that hysteresis in unemployment is absorbed by the labour market covariates, and thereby can be explained by the insider-outsider theory. Therefore, the information contained in the proxies of the insider-outsider theory affects the power of the unit root test, indicating that the unemployment rate in OECD countries does not display hysteretic behaviour.

To supplement the above ADF panel unit root testing framework, we employ a three-step testing strategy, which utilizes a semi-parametric fractional integration approach, to check for the presence of a unit root in unemployment rate (see among others, Shimotsu and Phillips, 2005; Kumar and Okimoto, 2007; Shimotsu, 2010; Christopoulos and McAdam, 2017). This approach is independent from the hypothesis that the labour market covariates are endogenous or exogenous, while it has also been demonstrated that the performance of these semi-parametric fractional integration estimators is unaffected by the endogeneity of the covariates as additional regressors (Velasco, 2006; Shimotsu, 2012; Christopoulos and McAdam, 2017).$^{10}$ A detailed description of this test is presented in the online appendix.

\section{Empirical results}

Tables 3 and 4 present the results for our unbalanced sample of 21 OECD countries based on the alternative panel unit root tests for the unemployment rate without and with covariates, both in the case of an intercept and that of an intercept and a linear trend. ${ }^{11}$ Specifically, Table 3 displays the results of the tests without the covariates: the $M W, C H, I P S$ tests and the CIPS test that accounts also for cross-sectional correlation. All tests, clearly, do not allow us to reject the null of a unit

\footnotetext{
${ }^{10}$ We would like to thank an anonymous referee for pointing out this issue.

${ }^{11}$ Following Pesaran et al. (2013), we use the lag augmentation order for the panel tests according to $p=$ $\left[4(\mathrm{~T} / 100)^{1 / 4}\right]$.
} 
root in the unemployment rate at the 5\% level of significance, indicating that unemployment exhibits pronounced hysteretic behaviour for the panel of OECD countries. ${ }^{12}$ These results reaffirm the previous findings for the OECD economies (for example, Mitchell, 1993 and Røed, 1996) and imply that the impact of a temporary shock on unemployment last longer and will lead to a permanent rise in the level of unemployment (Lindbeck and Snower, 2002).

\section{- Table 3 here -}

Table 4 presents the results of the covariate CIPSM panel unit root test of Pesaran et al. (2013), that allow us to control for the addition of the insider-outsider covariates (Union, Coord and $\mathrm{Wbl}$ ). To explore the robustness of the test to the choice of the additional covariates used in the ADF panel augmentation in Equation (1), we report the results of the CIPSM test using all possible combinations of these covariates, as well as using their first principal component (Power). In contrast to the previous outcome of the tests without covariates, the evidence based on the CIPSM covariate panel unit root test shows that the null hypothesis of a unit root in the panel is strongly rejected at the $5 \%$ (in 10 out of 16 cases) or $10 \%$ significance level (in 3 cases) for all possible covariates and for most of the alternative combinations of them. The only exceptions are in the case of using Coord as the additional covariate where the CIPSM test does not reject the null in the version with trend and the cases where the two covariates (Coord and $W b l$ ) and the three covariates (Union, Coord and $\mathrm{Wbl}$ ) are used in the version with trend, where the null cannot be

\footnotetext{
${ }^{12}$ This evidence is also confirmed by the individual ADF unit root tests for each country. These results show that for all 21 OECD countries we cannot reject the null of a unit root (with the exception of the version with trend where the results hold for the vast majority of the countries, i.e., 20 out of 21 countries). This is a strong evidence of hysteresis for the OECD sample. These results are available from the authors upon request.
} 
rejected at the conventional levels of significance. ${ }^{13}$

\section{- Table 4 here -}

These results suggest that while we find a strong evidence of hysteretic behaviour of unemployment for the OECD countries when we use the panel tests without covariates, this result is completely reversed when we use the tests that allow for the insider-outsider covariates. The inclusion of the proxies makes the unemployment rate stationary, leading to the conclusion that the hysteretic behaviour of unemployment can be explained by the insider-outsider theory. Insiders' power, thus, determines the level of unemployment persistence through labour market rigidities and turnover costs (Lindbeck and Snower, 1988). Therefore, a transitory shock to the economy will lead to the reduction of the number of insiders by firms and the subsequent rise of wages by the remaining insiders (as a result of their higher job security) as well as the discourage of future employment (Lindbeck and Snower, 2002). Labour market rigidities, and in particular high turnover costs associated with insiders' power, inhibit the ability of the economy to absorb the shocks in unemployment in OECD countries.

\section{Further results and robustness}

In order to check whether our results are sensitive to the potential endogeneity of the labour market covariates we implement a three-step testing strategy that uses a semi-parametric fractional unit root approach based on Shimotsu and Phillips (2005), Shimotsu (2010) and Christopoulos and McAdam (2017). To do so, we estimate the long memory parameter $(d)$ using the semi-parametric

\footnotetext{
${ }^{13}$ Our results are robust to alternative sets of OECD countries. In the robustness section we have employed the tests to a sub-sample of 17 OECD countries. The results are consistent with those from the sample of the 21 OECD countries. In addition, we have explored the set of the 15 OECD countries used in Mitchell (1993) and Song and Wu (1998) with qualitatively similar findings. These results are available from the authors upon request.
} 
two-step ELW estimator for the unemployment rate and the residuals from the models with the labour market covariates. Consistent with our previous results, the fractional unit root tests (Table 5) show that the unemployment rate has a unit root as the estimated long memory parameter exceeds unity $\left(\hat{d}^{U}>1\right)$. When we estimate the $d$ parameter for the residuals, based on the models with the insider-outsider covariates, we can observe that the null hypothesis of a unit root is rejected for all measures, $\hat{d}^{e}<1$. Additionally, we can observe that the covariate long memory parameters, in all cases, are well below of that from the unconditional parameter, $\hat{d}^{e}<\hat{d}^{U}$, which is a clear indication that the insider-outsider covariates stabilize unemployment, and, thus, signaling that hysteresis in unemployment in OECD countries can be elucidated by these labour market covariates.

\section{- Table 5 here -}

Our main objective is to test the role of the insider-outsider theory as a cause of hysteresis, however, it is interesting to check whether other labour market frictions can explain unemployment persistence. Therefore, we extend our analysis by using various additional covariates for our sample of OECD countries. ${ }^{14}$ The new covariates are the minimum wage $(M w)$, unemployment insurance and unemployment assistance benefits proxied by the gross replacement rate (Grr), two measures of strictness of employment protection for regular contracts (Epr) and temporary employment (Ept) and severance pay at three levels of tenure; 9 months (Sev1), 4 years (Sev2) and 20 years (Sev3). We follow Banker et al. (2013) by employing an unweighted average of Epr and

\footnotetext{
${ }^{14}$ We also implement the analysis using the additional covariates of labour market frictions for the subsample of $17 \mathrm{OECD}$ countries that is used in the robustness section. The results are qualitatively similar with those based on the sample of the 21 OECD countries. However, the reader should interpret all these results, based on the additional covariates, with caution due to data limitations and the low power of the tests in small size. These additional results are available from the authors upon request.
} 
Ept (and similarly of Sev1, Sev2 and Sev3) to create an aggregate measure of employment protection, $\mathrm{Epl}$ (and of severance pay, Sev). The source of these additional covariates is the OECD and, specifically, the labour force statistics $(M w)$, the benefits and wages database $(G r r)$ and the employment protection database (for all $\mathrm{Epl}$ and $\mathrm{Sev}$ indicators).

These covariates could influence unemployment persistence through different mechanisms. Unemployment benefits (Grr), for instance, affect the search intensity of unemployed workers and thereby discourage labour supply (Hagedorn et al., 2013). In addition, the minimum wage (Mw) can create involuntary unemployment by increasing labour cost, see Holmlund (2014). Employment protection legislation is a major source of hiring and firing costs thus may discourage job creation and increases the persistence of unemployment (Banker et al., 2013 and Holmlund, 2014). Therefore, we follow the literature, such as Banker et al. (2013), and use indexes of employment protection for both regular and temporary employees along with the average of these two indicators as an aggregate measure of employment protection legislation ( $E p l)$. Additionally, we test the effect of severance pay (Sev) which is one of the component of the Epl indicator that can affect labour demand as it associated with higher labour cost, see Garibaldi and Violante (2005).

Table 6 displays the results of the covariate CIPSM panel unit root test based on these covariates for the sample of 21 OECD countries. The results show that these additional covariates cannot explain the persistence of unemployment as we cannot reject the unit root null in almost all cases. The only exceptions are in the case of using Grr as the additional covariate where the CIPSM test rejects the null hypothesis of unit root but only in the version without trend and the case of using Sevl in the version of the test with trend. Overall, we cannot find sufficient evidence about the role 
of these covariates in explaining hysteresis in OECD countries. ${ }^{15}$

\section{- Table 6 here -}

Finally, to check for the robustness of our main findings, we conduct the panel unit root testing framework presented in Tables 3 and 4, including now the CSBM test that requires balance data, on the sub-sample of 17 OECD countries where data are available for the full period. ${ }^{16}$ This sample consists of the main 21 OECD countries, excluding Greece, New Zealand, Portugal and Spain to have a balanced panel. The results from the panel unit root test without covariates for the 17 OECD countries, presented in Table 7, show that unemployment rate exhibits a unit root behaviour, confirming the findings based on the 21 OECD sample. We then move to apply the CIPSM and $C S B M$ covariate panel unit root tests in the balanced data set of the 17 OECD countries. The findings from the CIPSM test are consistent with our previous results from Table 4. Particularly, the null hypothesis of a unit root in the panel is rejected at conventional levels of statistical significance in 13 out of 16 cases, for the individual covariates and the alternative combinations of them, see Table 8 . The results based on the CSBM test are similar and reveal stronger evidence of rejection of the null hypothesis of hysteresis for all sixteen cases of choices of covariates. Thus, our results are robust across different samples and tests and demonstrate that unemployment exhibits hysteretic behaviour in OECD countries and insiders' power is a key source of this behaviour.

\footnotetext{
${ }^{15}$ Recalling the data limitation for these additional covariates, the reader has to be careful so as to not interpret these findings as evidence against the ability of other theories to explain hysteresis.

${ }^{16}$ The $C S B M$ test of Pesaran et al. (2013) is based on the average of the cross-sectionally augmented SarganBhargava statistics, $\operatorname{CSBM}=N^{-1} \sum_{i=1}^{N} \operatorname{CSB}_{\phi_{i}}(N, T)$, where $\operatorname{CSB}_{\phi_{i}}(N, T)=T^{-2} \sum_{t=1}^{T} \hat{u}_{i t}^{2} / \hat{\sigma}_{i}^{2}, \hat{u}_{i t}=$ $\sum_{j=1}^{t} \hat{\varepsilon}_{i j}, \hat{\sigma}_{i}^{2}=\sum_{\tau=1}^{T} \hat{\varepsilon}_{i t}^{2} /[T-(k+1)]$ and finally $\hat{\varepsilon}_{i t}$ are the residuals from the regression of Equation (1).
} 


\section{- Table 7 here -}

\section{- Table 8 here -}

Overall, our results suggest that the insider-outsider covariates can help to explain the hysteretic behaviour of OECD unemployment, and this outcome is robust to alternative samples and testing methods, while we cannot find any sufficient evidence about the role of other measures of labour market frictions in explaining hysteresis in OECD countries. Our findings shed light on the role of the insider-outsider theory as a key source of unemployment persistence, confirming the theoretical underpinnings of the works by Blanchard and Summers $(1986,1987)$ and Lindbeck and Snower (1988) and show that various indicators of labour markets rigidities that capture the insiders' power and labour turnover cost can explain the hysteretic behaviour of unemployment in OECD countries.

\section{Conclusion}

Despite the widespread use of insider-outsider theory to describe the hysteretic behaviour of unemployment, little is known empirically about its validity as a cause of this behaviour. Using proxies of insiders' power, this paper investigates empirically the relationship between insideroutsider theory and unemployment hysteresis. To do so, we employ covariate panel unit root tests on a sample of 21 OECD countries over the period 1960-2013. Our initial findings provide evidence of hysteretic behaviour of unemployment for our sample. However, we find that the insider-outsider theory, proxied by the trade union density, the coordination of wage-setting and the level of wage-bargaining, can absorb the persistence of unemployment rate in OECD countries. 
Our findings suggest that policy makers should account for the impact of labour markets rigidities, which embed the power of the insiders, when introducing policies that aim at the structural characteristics of the economy and, thus, direct the economy to absorb the unemployment shocks. The power of the insiders implies higher turnover costs, thereby it adversely affects labour demand. Thus, shocks in unemployment tend to last for longer period. Our results illustrate the importance of structural reforms in the OECD labour markets towards lower labour market rigidities, and especially less power of the insiders, in order to stabilize unemployment in the face of shocks. In particular, limiting the role of trade unions, reforming job security regulations, and/or reducing the wage-bargaining level could lead to lower unemployment persistence. 


\section{References}

Arestis, P., and Mariscal, I.B.F. (1999). Unit roots and structural breaks in OECD unemployment. Economics Letters, 65, 149-156.

Bakas, D., and Papapetrou, E. (2014). Unemployment by gender: Evidence from EU countries. International Advances in Economic Research, 20, 103-111.

Banker, R. D., Byzalov, D., and Chen, L. T. (2013). Employment protection legislation, adjustment costs and cross-country differences in cost behavior. Journal of Accounting and Economics, $55,111-127$.

Belot, M., and van Ours, J.C. (2001). Unemployment and labor market institutions: an empirical analysis. Journal of the Japanese and International Economies, 15, 1-16.

Belot, M., and van Ours, J.C. (2004). Does the recent success of some OECD countries in lowering their unemployment rate lie in the clever design of their labor market reforms? Oxford Economic Papers, 56, 621-642.

Berthold, N. and Fehn, R. (1996). The positive economics of unemployment and labor market inflexibility. Kyklos, 49, 583-613.

Blanchard, O.J., and Summers, L.H. (1986). Hysteresis and the European unemployment problem. NBER Macroeconomics Annual, 1, 15-78.

Blanchard, O.J., and Summers, L.H. (1987). Hysteresis in unemployment. European Economic Review, 31, 288-295. 
Camarero, M., and Tamarit, C. (2004). Hysteresis vs. natural rate of unemployment: New evidence for OECD countries. Economics Letters, 84, 413-417.

Choi, I. (2001). Unit root tests for panel data. Journal of International Money and Finance, 20, 249-272.

Christopoulos, D., and McAdam, P. (2017). Do financial reforms help stabilize inequality?. Journal of International Money and Finance, 70, 45-61.

Cross, R. (ed.) (1988), Unemployment, hysteresis and the natural rate hypothesis. Basil Blackwell, Oxford.

Davidsson, J.B., and Emmenegger, P. (2013). Defending the organisation, not the members: Unions and the reform of job security legislation in Western Europe. European Journal of Political Research, 52, 339-363.

Emmenegger, P. (2009). Barriers to entry: Insider/outsider politics and the political determinants of job security regulations. Journal of European Social Policy, 19, 131-146.

Friedman, M. (1968). The role of monetary policy. American Economic Review, 58, 1-17.

Garibaldi, P., and Violante, G. L. (2005). The employment effects of severance payments with wage rigidities. The Economic Journal, 115, 799-832.

Gottfries, N., and Horn, H. (1987). Wage formation and the persistence of unemployment. The Economic Journal, 97, 877-884. 
Hagedorn, M., Karahan, F., Manovskii, I., and Mitman, K. (2013). Unemployment benefits and unemployment in the great recession: the role of macro effects. Working Paper No. 19499, NBER, Cambridge, MA.

Heidenreich, M. (2015). The end of the honeymoon: The increasing differentiation of (long-term) unemployment risks in Europe. Journal of European Social Policy, 25, 393-413.

Holmlund, B. (2014). What do labor market institutions do?. Labour Economics, 30, 62-69.

Im, K.S., Pesaran, M.H., and Shin, Y. (2003). Testing for unit roots in heterogeneous panels. Journal of Econometrics, 115, 53-74.

Jaeger, A., and Parkinson, M. (1994). Some evidence on hysteresis in unemployment rates. European Economic Review, 38, 329-342.

Kumar, M. S., and Okimoto, T. (2007). Dynamics of persistence in international inflation rates. Journal of Money, Credit and Banking, 39, 1457-1479.

Layard, R., and Bean, C. (1989). Why does unemployment persist?. The Scandinavian Journal of Economics, 91, 371-396.

Lindbeck, A., and Snower, D. (1988). The insider-outsider theory of employment and unemployment. MIT Press, Cambridge, MA.

Lindbeck, A., and Snower, D. (2001). Insiders versus outsiders. Journal of Economic Perspectives, $15,165-188$.

Lindbeck, A., and Snower, D. (2002). The Insider-outsider theory: A survey. IZA Discussion Papers 534. Institute for the Study of Labor (IZA), Bonn. 
Maddala, G.S., and Wu, S. (1999). A comparative study of unit root tests with panel data and a new simple test. Oxford Bulletin of Economics and Statistics, 61, 631-652.

Mitchell, W.F. (1993). Testing for unit roots and persistence in OECD unemployment rates. Applied Economics, 25, 1489-1501.

Nickell, S. (2003). Labour market institutions and unemployment in OECD countries. CESifo DICE Report, 1, 13-26.

O’Shaughnessy, T. (2011). Hysteresis in unemployment. Oxford Review of Economic Policy, 27, $312-337$

Pesaran, M.H. (2007). A simple panel unit root test in the presence of cross-section dependence. Journal of Applied Econometrics, 22, 265-312.

Pesaran, M.H., Smith, L.V., and Yamagata, T. (2013). Panel unit root tests in the presence of a multifactor error structure. Journal of Econometrics, 175, 94-115.

Phelps, E.S. (1968). Money-wage dynamics and labor-market equilibrium. Journal of Political Economy, 76, 678.

Røed, K. (1996). Unemployment hysteresis-macro evidence from 16 OECD countries. Empirical Economics, 21, 589-600.

Røed, K. (1997). Hysteresis in unemployment. Journal of Economic Surveys, 11, 389-418.

Saint-Paul, G. (2004). Why are European countries diverging in their unemployment experience?. The Journal of Economic Perspectives, 18, 49-68. 
Shimotsu, K. (2010). Exact local Whittle estimation of fractional integration with unknown mean and time trend. Econometric Theory, 26, 501-540.

Shimotsu, K. (2012). Exact local Whittle estimation of fractionally cointegrated systems. Journal of Econometrics, 169, 266-278.

Shimotsu, K., and Phillips, P.C. (2005). Exact local Whittle estimation of fractional integration. The Annals of Statistics, 33, 1890-1933.

Song, F.M., and Wu, Y. (1998). Hysteresis in unemployment: Evidence from OECD countries. The Quarterly Review of Economics and Finance, 38, 181-192.

Velasco, C., (2006). Semiparametric estimation of long-memory models. In: Patterson, K., Mills, T.C. (Eds.), Handbook of Econometrics, vol. 1. Econometric Theory. Palgrave: MacMillan, 353-395.

van Ours, J.C. (2015). The Great Recession was not so great. Labour Economics, 34, 1-12. 


\section{Tables and figures}

Table 1: Summary Statistics

\begin{tabular}{lcccr}
\hline Variable & Mean & Std. Dev. & Minimum & Maximum \\
\hline Un. Rate & 5.816 & 4.127 & 0.000 & 27.306 \\
Union & 39.545 & 18.806 & 7.548 & 83.863 \\
Coord & 3.221 & 1.383 & 1.000 & 5.000 \\
Wbl & 3.085 & 1.336 & 1.000 & 5.000 \\
$\begin{array}{l}\text { Power } \\
\text { Notes: Descriptive statistics for the OECD sample, based on N }=21 \text { and T }=54(\mathrm{TxN}=1134 \text { Obs). }\end{array}$ & \\
$\begin{array}{l}\text { Source: Authors' calculations. } \\
\text { N }\end{array}$ & 0.000 & 1.433 & -2.689 & 2.848 \\
\end{tabular}

Table 2: Correlation Coefficients between Covariates

\begin{tabular}{lrrr}
\hline & Union & Coord & Wbl \\
\hline Union & 1 & & \\
Coord & 0.456 & 1 & \\
Wbl & 0.513 & 0.729 & 1
\end{tabular}

Notes: The numbers refer to the Polyserial or Polychoric correlation coefficient depending on the type of the variables. Source: Authors' calculations.

Table 3: Panel Unit Root Tests (without Covariates)

\begin{tabular}{|c|c|c|c|c|c|c|c|c|}
\hline \multirow[t]{3}{*}{ Un. Rate } & \multicolumn{4}{|c|}{ Without Trend } & \multicolumn{4}{|c|}{ With Trend } \\
\hline & $M W$ & $\mathrm{CH}$ & $I P S$ & CIPS & $M W$ & $\mathrm{CH}$ & $I P S$ & CIPS \\
\hline & 31.689 & 0.394 & -1.472 & -1.901 & 34.802 & 0.503 & -2.107 & -2.246 \\
\hline
\end{tabular}


Table 4: Panel Unit Root Tests (with Covariates)

\begin{tabular}{|c|c|c|}
\hline \multirow[b]{2}{*}{ Covariates } & \multicolumn{2}{|c|}{ CIPSM } \\
\hline & Without Trend & With Trend \\
\hline Union & $-2.630^{* *}$ & $-2.863^{* *}$ \\
\hline Coord & $-2.227^{*}$ & -2.584 \\
\hline$W b l$ & $-2.568^{* *}$ & $-2.648^{*}$ \\
\hline Power & $-2.686^{* *}$ & $-2.743^{* *}$ \\
\hline Union \& Coord & $-2.609^{* *}$ & $-2.813^{* *}$ \\
\hline Union \& Wbl & $-2.497^{* *}$ & $-2.802^{* *}$ \\
\hline Coord \& Wbl & $-2.714^{* *}$ & -2.554 \\
\hline Union \& Coord \& Wbl & $-2.472^{*}$ & -2.486 \\
\hline
\end{tabular}

Notes: ${ }^{*},{ }^{*}$ indicate rejection of the null hypothesis of a unit root at the $5 \%$ and $10 \%$ significance level respectively. The critical values for the CIPSM test, in the case of one additional covariate, are -2.32 and -2.21 with an intercept only and 2.73 and -2.63 with an interept and a linear trend for the $5 \%$ and $10 \%$ significance levels, respectively. In addition, the critical values for the CIPSM test (with two additional covariate) with an intercept only are -2.43 and -2.31 and with an interept and a linear trend are -2.80 and -2.68 for the $5 \%$ and $10 \%$ significance levels, respectively. Finally, the critical values for the CIPSM test (with three additional covariate) with an intercept only are -2.49 and -2.37 and with an interept and a linear trend are -2.81 and -2.69 for the $5 \%$ and $10 \%$ significance levels, respectively. The lag order is selected according to $p=\left[4(\mathrm{~T} / 100)^{1 / 4}\right]$.

Source: Authors' calculations. 
Table 5: Panel Fractional Unit Root Tests (with Covariates)

\begin{tabular}{|c|c|}
\hline & $\hat{d}_{E L W}$ \\
\hline Un. Rate & $1.044(0.158)$ \\
\hline \multicolumn{2}{|l|}{ Covariates } \\
\hline Union & $0.947(0.158)$ \\
\hline Coord & $0.843(0.158)$ \\
\hline Wbl & $0.861(0.158)$ \\
\hline Power & $0.981(0.158)$ \\
\hline
\end{tabular}

Notes. Standard errors in parenthesis.

Source: Authors' calculations.

Table 6: Panel Unit Root Tests (with Additional Covariates)

\begin{tabular}{|c|c|c|}
\hline \multirow[b]{2}{*}{ Covariates } & \multicolumn{2}{|c|}{ CIPSM } \\
\hline & Without Trend & With Trend \\
\hline$M w$ & -1.799 & -2.404 \\
\hline Grr & $-2.333^{* *}$ & -2.567 \\
\hline$E p l$ & -1.938 & -2.367 \\
\hline Epr & -1.576 & -2.172 \\
\hline Ept & -1.961 & -2.197 \\
\hline Sev & -1.232 & -1.979 \\
\hline Sev1 & -1.971 & $-2.720^{* *}$ \\
\hline Sev2 & -1.103 & -2.382 \\
\hline Sev3 & -1.528 & -2.142 \\
\hline
\end{tabular}


Table 7: Panel Unit Root Tests (without Covariates) - 17 OECD Countries

Un. Rate Without Trend With Trend

\begin{tabular}{ccccccccc}
\hline MW & CH & IPS & CIPS & & MW & CH & IPS & CIPS \\
\hline 28.770 & -0.319 & -1.612 & -2.005 & & 30.349 & 0.306 & -2.133 & -2.523
\end{tabular}

Notes: ${ }^{* *},{ }^{*}$ indicate rejection of the null hypothesis of a unit root at the $5 \%$ and $10 \%$ significance level respectively. The lag order is selected according to $p=\left[4(\mathrm{~T} / 100)^{1 / 4}\right]$.

Source: Authors' calculations.

Table 8: Panel Unit Root Tests (with Covariates) - 17 OECD Countries

\begin{tabular}{|c|c|c|c|c|}
\hline \multirow[b]{2}{*}{ Covariates } & \multicolumn{2}{|c|}{ Without Trend } & \multicolumn{2}{|c|}{ With Trend } \\
\hline & CIPSM & CSBM & CIPSM & CSBM \\
\hline Union & $-2.824^{* *}$ & $0.143^{* *}$ & $-2.927^{* *}$ & $0.080^{* *}$ \\
\hline Coord & -2.117 & $0.125^{* *}$ & -2.598 & $0.098^{*}$ \\
\hline Wbl & $-2.561^{* *}$ & $0.137^{* *}$ & $-2.667^{*}$ & $0.082^{* *}$ \\
\hline Power & $-2.620^{* *}$ & $0.140^{* *}$ & $-2.733^{* *}$ & $0.087^{* *}$ \\
\hline Union \& Coord & $-2.678^{* *}$ & $0.144^{* *}$ & $-3.020^{* *}$ & $0.079^{* *}$ \\
\hline Union \& Wbl & $-2.716^{* *}$ & $0.135^{* *}$ & $-2.948^{* *}$ & $0.073^{* *}$ \\
\hline Coord \& Wbl & $-2.545^{* *}$ & $0.121^{* *}$ & -2.555 & $0.084^{*}$ \\
\hline Union \& Coord \& Wbl & $-2.477^{*}$ & $0.153^{* *}$ & $-2.778^{*}$ & $0.074^{*}$ \\
\hline \multicolumn{5}{|c|}{$\begin{array}{l}\text { Notes: }{ }^{*},{ }^{*} \text { indicate rejection of the null hypothesis of a unit root at the } 5 \% \text { and } 10 \% \text { significance level respectively. The } \\
\text { critical values for the CIPSM test with one additional covariate, are }-2.32 \text { and }-2.21 \text { with an intercept only and }-2.73 \text { and - } \\
2.63 \text { with an interept and a linear trend for the } 5 \% \text { and } 10 \% \text { significance levels, respectively. The critical values with two } \\
\text { additional covariates with an intercept only are }-2.43 \text { and }-2.31 \text { and with an interept and a linear trend are }-2.80 \text { and }-2.68 \text {. } \\
\text { The critical values with three additional covariates with an intercept only are }-2.49 \text { and }-2.37 \text { and with an interept and a } \\
\text { linear trend are }-2.81 \text { and }-2.69 \text {. In addition, the critical values for the } C S B M \text { test with one additional covariate, are } 0.238 \\
\text { and } 0.264 \text { with an intercept only and } 0.097 \text { and } 0.104 \text { with an interept and a linear trend for the } 5 \% \text { and } 10 \% \text { significance } \\
\text { levels, respectively. The critical values with two additional covariates with an intercept only are } 0.207 \text { and } 0.231 \text { and with } \\
\text { an interept and a linear trend are } 0.084 \text { and } 0.090 \text {. Finally, the critical values with three additional covariates with an } \\
\text { intercept only are } 0.178 \text { and } 0.200 \text { and with an interept and a linear trend are } 0.072 \text { and } 0.078 \text {. The lag order is selected } \\
\text { according to } p=\left[4(\mathrm{~T} / 100)^{1 / 4}\right] \text {. } \\
\text { Source: Authors' calculations. }\end{array}$} \\
\hline
\end{tabular}


Figure 1: Unemployment Rate for the 21 OECD Countries against the OECD Average
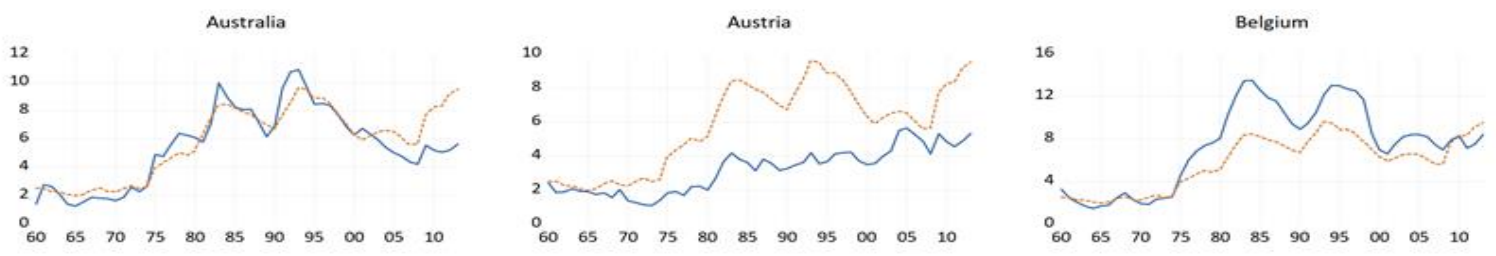

$\begin{array}{lllllllllll}06 & 65 & 70 & 75 & 80 & 85 & 90 & 95 & 00 & 05 & 10\end{array}$
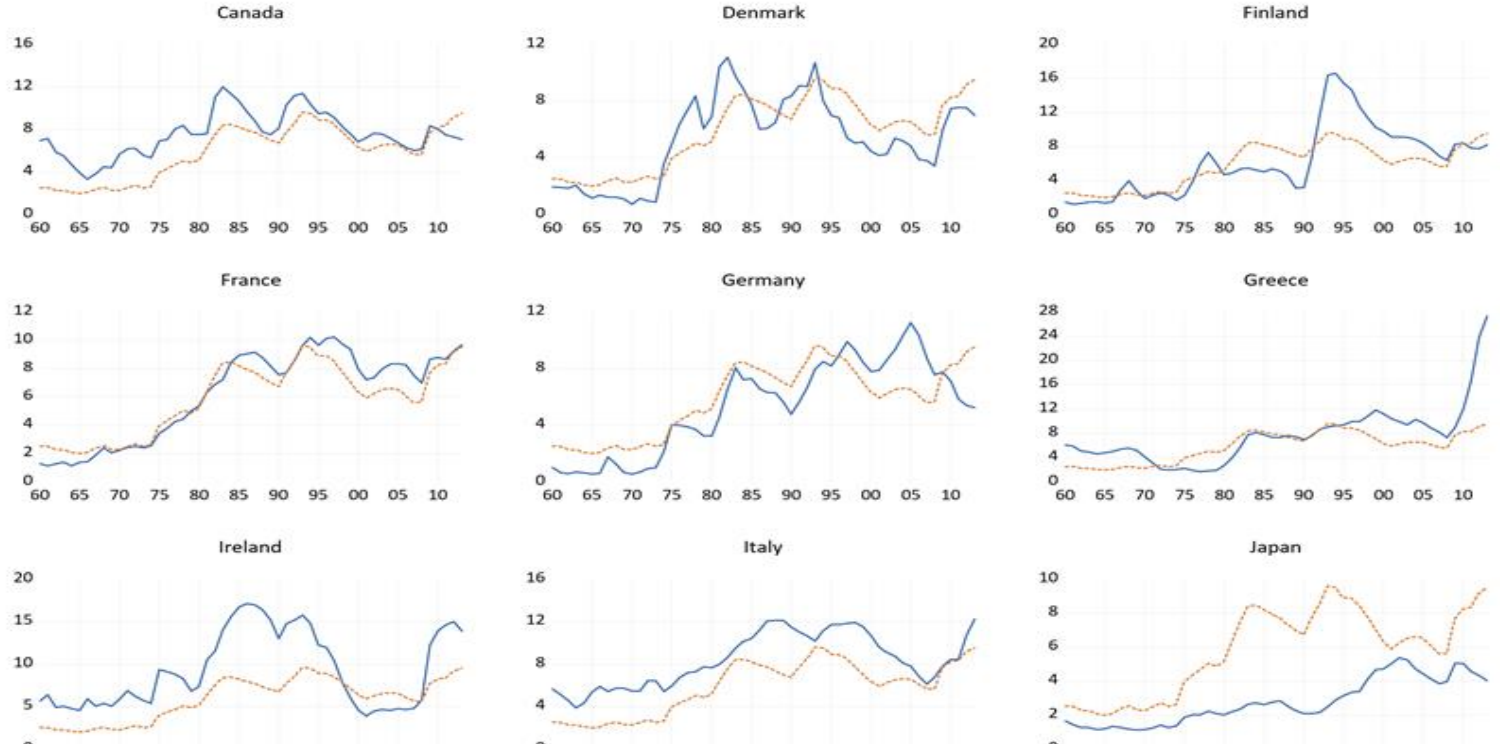

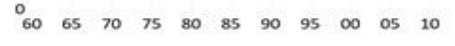

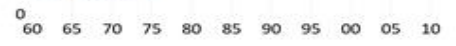

$\begin{array}{lllllllllll}60 & 65 & 70 & 75 & 80 & 85 & 90 & 95 & 0 & 05 & 10\end{array}$
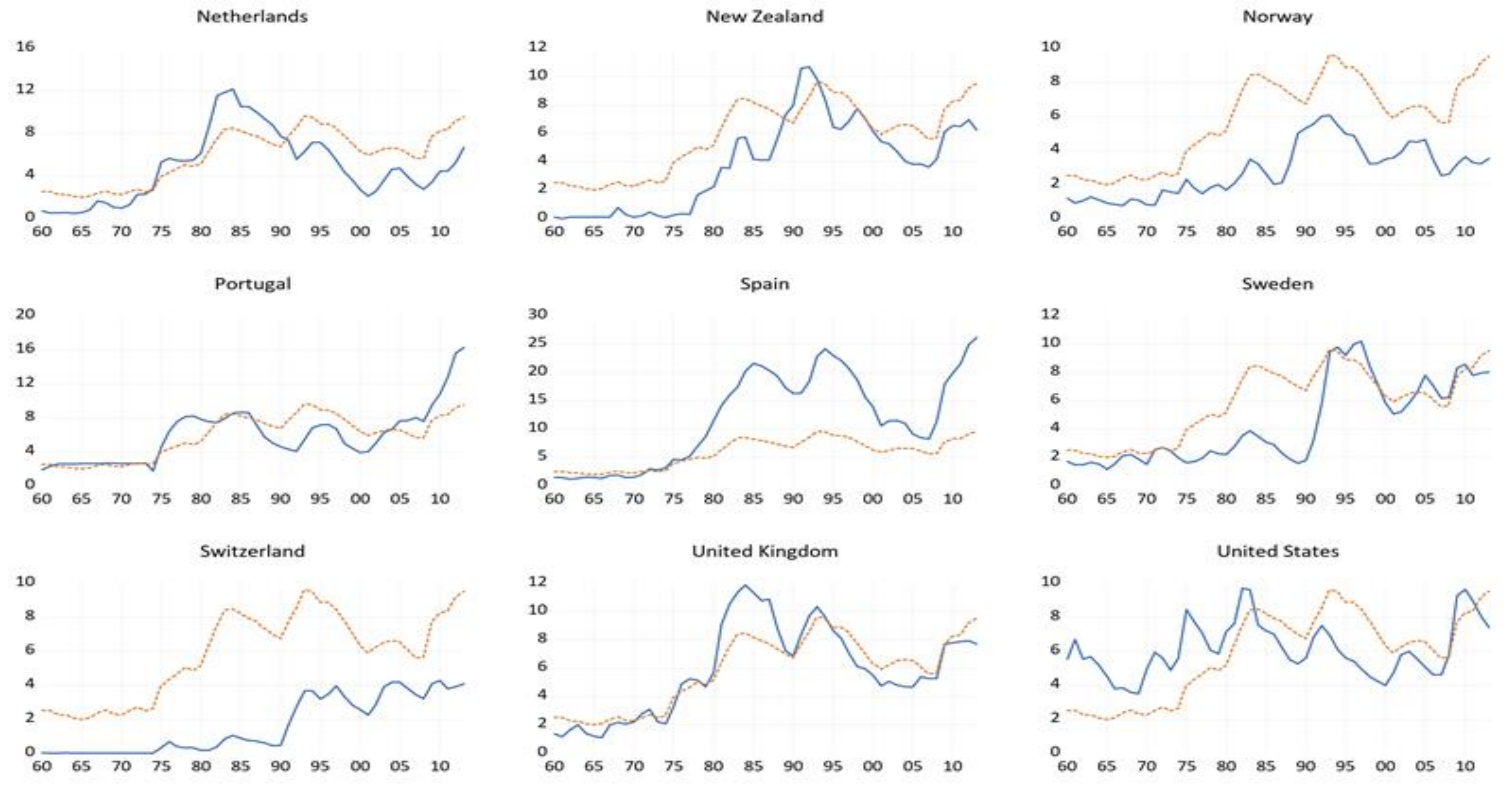

Source: Authors' calculations. 